\title{
The ideology of communication practices embedded in an Australian deaf/hearing dance collaboration
}

\section{Introduction}

What happens when deaf signers of Auslan and hearing non-signing speakers of English and other languages collaborate on a choreographed contemporary dance performance? How do they communicate during the development and rehearsal stages of the project, and what does the final performance look like? A curious observer might speculate that the artists would converse using Auslan and English, perhaps through signed language interpreters; occasionally writing things down, while also making recourse to gesture, movement, and lip-reading when necessary. But does this really happen, and uniformly across individuals? This chapter describes the on-the-ground communication practices that were developed during an Australian deaf/hearing contemporary dance collaboration, with the aim of furthering our understanding of how these practices are performed in everyday life. ${ }^{1}$

Deaf people habitually draw upon multilingual, multimodal communication practices in their everyday language use, especially during interactions with non-signing people. Yet our understanding of how individual communicative repertoires manifest within specific interactions and across social networks is still developing. Scholars from disciplines such as education, anthropology and linguistics have analysed a range of everyday social acts (see Kusters, Spotti, Swanwick \& Tapio, 2017, for an overview). For example, researchers have investigated sign bilingualism in the classroom (e.g. Bagga-Gupta, 2000), intra-familial interactions in communities with high rates of hereditary deafness and signed language use (e.g. Kisch, 2008; Nyst, 2012),

1 Acknowledgements: This research was supported by funding from the La Trobe University Social Research Assistance Platform and the UK Arts and Humanities Research Council (AH/NO0924X/1). The Delta Project (www.thedeltaproject.com.au) are produced by Arts Access Victoria. All images credited to Pippa Samaya. Many thanks to Arts Access Victoria and the members of The Delta Project: Fiona Cook (Producer), Jo Dunbar and Lina Limosani (Choreographers), Anna Seymour, Elvin Lam, Amanda Lever and Luigi Vescio (Dancers), Rhian Hinkley (Video Designer), Richard Vabre (Lighting Designer and Lighting Operator), and Russell Goldsmith (Composer \& Sound Designer). All artists in The Delta Project contributed to this research and were paid above award rates for their time. Thanks also to Brent Phillips, Daniel Hately and David Childs at Auslan Connections for interpreting support, and to Breda Carty, Lindsay Ferrara, Maeve McGreevy and the editors for their valuable comments on earlier versions of this chapter. Any errors are my own.

๑ Open Access. (c) 2020 Gabrielle Hodge, published by De Gruyter. @BY-NC-ND This work is licensed under the Creative Commons Attribution-NonCommercial-NoDerivatives 4.0 License.

https://doi.org/10.1515/9781501510090-004 
transmodal interpretation and translation practices (e.g. Adam, Carty \& Stone, 2011), deaf multilingual and cross-modal practices (e.g. Tapio, 2013; Quinto-Pozos \& Adam, 2013), customer/merchant exchanges (e.g. Kusters, 2017), creative collaborations involving deaf and hearing artists (e.g. Fagan Robinson, 2019), and interactions between deaf people without a common signed language (e.g. Byun, De Vos, Bradford, Zeshan \& Levinson, 2017). This study takes a tangential approach by investigating the emerging setting of deaf artists collaborating with hearing artists on a creative work performed live to a mixed deaf/hearing (non) signing audience.

Here I use moments from a filmed performance of Under My Skin, a two-hour group discussion, one-to-one interviews and email correspondence with the artists to articulate the language ideologies embedded in the final performance. The data demonstrate how human communicative repertoires (and therefore interactions) are shaped by a range of affordances, many of which may be characterised as covertly influencing communication and language use. These include the situated context of deaf signing ecologies within complex mainstream environments, the interpersonal agency of people interacting (e.g. specific embodiments, personal beliefs, habitual communication heuristics, and history of interactions), as well as more intangible aspects of our relationships to each other and immediate physical environs. Our understanding of language ideologies depends as much on these affordances as it does on overt ideas about languages and how they are used, especially in the context of communication practices developed through interactions with members of minority language groups.

\section{Communication and language ecologies}

The first step in investigating the communication practices that develop between signers and non-signers is to consider the language ecologies in which these practices emerge. Signers and speakers live in richly dynamic language ecologies, in which what we understand as 'language' is just one of many resources available for making meaning (Bühler, 1990/1934; Parmentier, 1994; Enfield, 2009; see Moriarty Harrelson, 2017, in relation to deaf signers specifically). Varied resources (a voice, hands, physical artefacts such as paper, sand, mobile phone) and modes of communication (sign, speech, computer icons, an alphabet) may combine in different ways, the details of which are rooted in the interactions occurring in a specific time and place. For example, in Finland, signing deaf children are educated in a highly multilingual school environment, where different signed languages, spoken languages, and formal systems for representing speech on the 
hands converge. In the context of learning English via online computer activities, Finnish deaf children often use fingerspelling to mediate their typing of English words. The manner of fingerspelling - such as careful or quick articulation, or negotiated with peers - depends on the specific online learning activity (Tapio, 2013). In the Western desert region of Australia, Ngaanyatjarra children may incorporate alphabetic symbols into their stories drawn in the sand, along with the more traditional iconographic drawings and objects used by adults to index and depict referents (such as humans, monsters and geographical locations) in these stories. This youth-driven contribution to established sand story practices reflects generational literacy differences (Kral \& Ellis, 2008; see also J. A. Green, 2014). Even within minority language ecologies, shared resources for making meaning and modes of communication may be used in different ways by different individuals at different times.

In this sense then, a language ecology is not simply the environment in which signers and speakers act; it is the constantly emerging complex shape and history of interactions between language users and their environment (Haugen, 1972; Goodwin, 2000). Encounters between agents in an ecology are developed and maintained over various time frames, with the effect that "future interactions occur in a new and adaptive way" (Pickering, 1997: 192). These small-scale social encounters shape larger scale practices and vice versa (Agha, 2005: 12). Consequently, communicative practices and repertoires differ, both within specific interactions and across social networks (Bourdieu, 1991; Agha, 2007; see also Bernstein, 2003[1971]). As with other minority language ecologies that do not have a loud public presence and codification pathway (via online print, television, radio and institutionalized domains of use), it is the small-scale encounters especially which shape deaf communication practices (including those developed with non-signers), because this is how deaf people most often encounter signed languages (see also Snoddon, 2017). Online blogs and other filmed signed events are becoming more common, and it could be argued that specific signs or ways of signing are becoming codified by internet mediums (e.g. the ILY sign). However, this does not occur to the extent possible for majority languages such as English, the use of which prevails over time in the domains of education, medicine, and the law (see also Eades, 2008, with respect to Indigenous Australian minority languages).

The tendency for less codification of practices can be partly attributed to the quintessentially face-to-face nature of interactions involving deaf people and signed language, "a fact that may influence, and even constrain, the linguistic [i.e. communicative] system in other ways" (Johnston, 1996: 1). While video technologies such as Skype and WhatsApp facilitate communication between signers in 
different geographical locations and time zones, it is not possible to 'disembody' signed communication into a singular, unimodal form in the way that looking away from the speaker, speaking down the telephone, or writing a letter does for spoken communication (Johnston, 1996: 7). For deaf people using a signed language, all interactions involve a continuation of visual and/or tactile access to another's multimodal, situated context: we can see or feel the other person moving in their environment, using all the communicative resources available to them in that moment and physical space. These influences and constraints manifest, for example, in the extensive and habitual integration of three types of signs (in a neo-Peircean sense) in face-to-face discourse: conventionalized signs (e.g. the words included in a dictionary and emblematic manual gestures such as THUMBS-UP), symbolic indexicals (i.e. deictic signs that have both conventional and non-conventional elements, such as pointing actions produced with an index finger), and tokens of non-conventional signs (such as improvised and mimetic bodily enactments of people, animals, or things) (Clark, 1996; Enfield, 2009; see also Ferrara \& Hodge, 2018). Compositions of these three types of signs are used to 'tell, point and show' during face-to-face interactions, and by extension, creative performances incorporating signed language.

Languages such as Auslan and English may therefore be considered as resources used by signers and speakers in acts of translanguaging, during which they draw on anything that is useful and available to them while engaging in social action (García, 2009; Blackledge \& Creese, 2010). The kinds of resources used represent an individual's communicative repertoire, defined as "the totality of linguistic and communicative possibilities, which are available to speakers [and signers] in specific situational contexts” (Busch, 2012: 169; see also Kusters et al. 2017). However, it is important to note that an individual's repertoire is as much determined by the resources they do not have, in addition to the resources they do have (Busch, 2015: 14). This factor gains prominence during interactions between deaf signers and hearing non-signers, as they must actively negotiate which bits of each other's repertoire can be used effectively (or not).

\section{Communication and the labor of understanding}

Central to this investigation is acknowledging the "labor of understanding" involved in communication, i.e. the work we do "to make understanding happen" (Friedner, 2016: 184). While all human communication seeks to establish common ground and achieve mutual understanding (Clark, 1996), a consequence of deafness is that one cannot take understanding for granted. Speech is often unintel- 
ligible to lip-readers, others frequently cannot interpret our varied, flexible, and yet often idiosyncratic means of communicating (or assume that they do, even when they do not $)^{2}$. Language is often "mediated" or "brokered" by other people (Kisch, 2008; Napier \& Leeson, 2016). For deaf signers, understanding and being understood may involve comparably more work than is required for status quo interactions between hearing speakers of heavily codified languages. This labor is integral to deaf socialities around the world, shaping the communicative practices that emerge in deaf language ecologies, and which are realised in specific interactions (E. M. Green, 2014; Friedner, 2016).

However, the labor of understanding is not simply the effort involved in comprehending individual signs and how they are composed into utterances, as the present study aims to demonstrate. It goes beyond language into the wider realm of committed intersubjectivity: the grounded experience of insightfully noticing and comprehending the myriad behaviors of another person (especially those with communicative intent), acting upon this insight empathetically, and enabling other people to do so in turn. As an ontology, it is also somewhat Janusfaced, its value dependent on both the presence and absence of acts of understanding: "as ungainliness is to grace - each seeing its essences, as absence, in the other" (Kockelman, 1999: 46). Describing the labor of understanding between signers and non-signers - and therefore realizing the value of this work to language ideologies - involves attending to both explicit and implicit ways in which we make ourselves understood, as well as the varying shades of misunderstanding (and even not-understanding) that occur (E. M. Green, 2014).

\section{Performing and experiencing a deaf/hearing dance collaboration}

Under My Skin is the second production from The Delta Project. It is a multimedia, multi-sensory contemporary dance performance that explores the idea of identity as a shared human experience: what we show and what we hide, and the corre-

\footnotetext{
2 Most deaf signers learn signed language from peers at school or as adults in the deaf community, rather than from their primary caregivers, resulting in signing ecologies that are extremely heterogeneous (Johnston, 2004). Much of the variation we see in deaf signing ecologies can therefore be directly attributed to systemic pressures and structural inequity, especially those resulting from various hegemonic medical and educational policies and technological advancements that have shaped deaf lives throughout the twentieth century.
} 
sponding struggle this brings. Choreographed by Jo Dunbar (deaf) and Lina Limosani (hearing), the narrative arc of the work begins with only glimpses of the four dancers entwined with each other in the darkness (Anna Seymour and Elvin Lam, both deaf, with Amanda Lever and Luigi Vescio, both hearing; see Figure 1). It is impossible to differentiate individuals clearly, and the impression of a single, alive entity comes from moving photographic images of their faces which play subtly over their bodies. Suddenly there is an explosive crack: the iceberg melts, the unity destroyed, each dancer a separate person. During the next forty minutes, the dancers are slowly unveiled: they are revealed, exposed, and ultimately realized as fully dimensional people, but only after a deeply cathartic journey that forces all to probe beneath their skin (especially where it hurts).
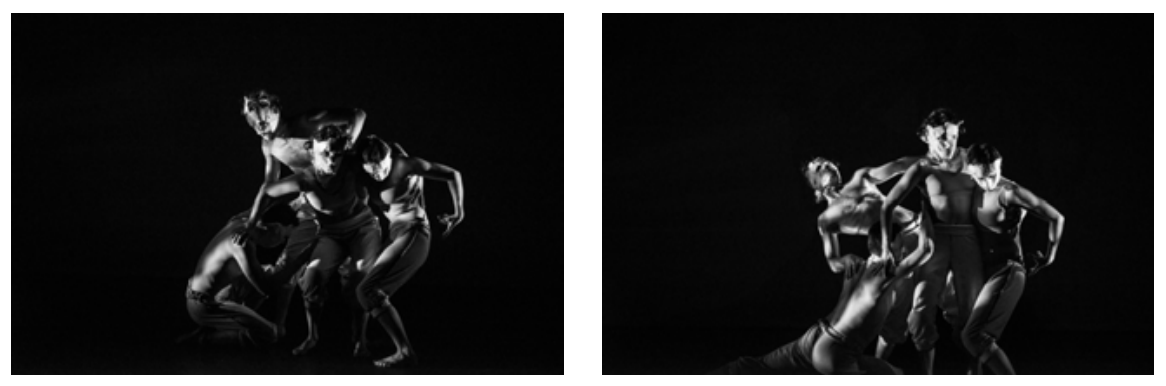

Figure 1. Dancers entwined in the darkness (image @ Pippa Samaya).

This performance of Under My Skin was a profoundly moving experience. It very effectively unpacked and reflected a shared human struggle to the audience, with a distinctly deaf flavor that resonated with both signing and non-signing viewers. As a deaf signer, Under My Skin left me with an overwhelming sense of feeling understood. On one level, it seems impossible to grasp what made it this way. On another level, there are more tangible aspects that are open to description, such as the interaction of different semiotic elements throughout the performance, and what these say about the worlds in which signers and speakers live. These include Auslan-based choreographed movement, kinaesthetically-driven sound composition, digital video design, and the interplay of light and shadow. In the following sections, I use moments from one filmed performance of Under My Skin, a two-hour group discussion, one-to-one interviews and email correspondence undertaken retrospectively with the artists, to articulate the language ideologies embedded in the final performance. 


\section{A fertile ground where saltwater and freshwater meet}

The Delta Project dance company was initially founded through a collaboration between deaf choreographer Jo Dunbar, deaf dancer Anna Seymour and hearing producer Fiona Cook at Arts Access Victoria in 2012. Together they directed the company into its current name and form. Jo, Anna and Elvin are all deaf from early childhood, belonging to hearing families, but each have different language histories. Their communicative repertoires are shaped by varied ages of signed language acquisition, and for Jo and Elvin, migration from other countries and languages. Anna and Elvin are predominantly signers, whereas Jo uses her voice often, switching between speech and sign depending on her interactions. Their vision for The Delta Project was to bring two worlds (deaf and hearing) together through visuals and sound to create a new dance aesthetic. As Anna explained in the group discussion ${ }^{3}$ :

The name is significant to us: a delta is the fertile ground where saltwater and freshwater meet. We wanted to create a dance performance that merged both deaf and hearing worlds, and was accessible to everyone in the audience. We also wanted to create opportunities for ourselves as professional dancers who are deaf, to raise our game and work with leading artists in the mainstream arts sector.

The hearing artists all learned English as their first language and do not use other languages, except for Luigi and Amanda. As the hearing artists who worked most closely with the deaf dancers, both Luigi and Amanda began to learn Auslan during the development and rehearsal stages of the project. Both can now communicate (to varied extents) with Anna, Elvin and Jo using the Auslan communication practices they developed. Amanda's signing ability is such that she occasionally interpreted for Anna and Elvin during rehearsals when there was no qualified interpreter available, or when there was a last-minute cancellation, as did Jo. All the hearing artists had worked with each other before this project. Overall Jo, Lina, Anna, Elvin, Luigi and Amanda had the most face-toface contact with each other. The social proximity of Rhian, Richard and Russell,

3 All translations from Auslan into English in this chapter were made by the deaf author (who shares deaf social networks in Melbourne), based on original or interpreted Auslan filmed during the group discussion at Arts Access Victoria on 4 April 2017, or derived from the Auslan-based movement in the performance filmed in May 2016. Some transcriptions of English were provided directly by the hearing artists in our interviews or written correspondence. 
as digital video, lighting and sound composition experts, increased only during the rehearsal and performing stages, towards the end of the project.

By inviting these hearing artists to work with them over many months, the deaf artists essentially tasked themselves with birthing a new language ecology. This was one in which the local signed language (Auslan) was explicitly valued along with the ambient spoken language (Australian English), but in which the hearing artists were implicitly tasked with learning to see and do things as deaf people. In other words, everyone was required to expand their communicative repertoires and reorient their habitual communication practices to the translanguaging demands of the collaboration. Present at this birth was a team of five qualified Auslan/English interpreters working with the artists, who were described as integral to the creative process (as Anna explained, "they see and feel the pain too"). Interpreters were usually booked in teams of two: one working with Jo from the choreographer perspective, and the other working with Anna and Elvin from the dancer perspective (each role involving different actions in the theatre space). While the deaf artists are well-versed in tailoring their communicative repertoires to non-signers (by dint of being minority language signers used to doing this kind of work), the hearing artists varied in how they responded to these demands, especially with respect to communicative adaptations.

\section{Managing the demands of time and space}

The presence of interpreters during the development and rehearsal stages of the project made one challenge immediately apparent: the physical demands of time and space. In mainstream collaborations, the development of dance choreography typically relies on the potential for dancers to simultaneously interpret visual and auditory instructions from the choreographer(s), and respond to these instructions instantly. However, this practice does not work in an environment in which deaf signers, hearing non-signers, and interpreters are communicating in different ways while moving throughout a physical space. As it is not possible for signers to visually attend to two different things at the same time, deaf dancers cannot both watch the interpreter, and simultaneously interpret and react to the choreographer's bodily instructions. Instead, consecutive communication practices are required during the development and rehearsal stages. Lina, the hearing choreographer, particularly struggled with this constraint on her established technical method: 


\begin{abstract}
As a choreographer, I vibrate on quite a fast level: I think fast, I see things quickly, and I react immediately. This pace was not so easy for me to work at during this project. Having to rely on a third party, the interpreters, to pass on information was a new experience for me. This process forced me to be patient, and 'slow down', as the speed at which I would speak and demonstrate was difficult for the interpreters to keep up with, and therefore unable to pass on the information to the deaf artists clearly...Some interpreters interpret words differently, so there were moments when directions were not explained as accurately as I had desired. Information would get missed for the deaf artists simply because they are constantly having to draw their focus between the interpreter and myself, especially when I was demonstrating physical instructions or movement.
\end{abstract}

Implicit in Lina's comments are two beliefs that had significant impact on the evolution of the project. Firstly, the belief that her role as a mainstream professional choreographer was to mentor the deaf artists 'up to the level' of the hearing dancers and hearing ways of doing dance. This belief was shaped by her invited collaboration with Jo, who explicitly sought a mentor in contemporary dance choreography and with whom she worked equitably together outside of the studio. Yet it also contradicts other aims expressed by the deaf artists, which were to draw from both established practices and their own embodied ways of being to develop a new way of doing dance (see §5). Secondly, the belief that there are simply two languages at play, that most instruction would be unidirectional (from English into Auslan), at least during the development of dance choreography, and that the interpreters were mostly responsible for doing this mediation work (even if their interpretation was sometimes not accurate enough). Both beliefs point to a more general confusion about the effects of different bodies - deaf and hearing - on a space. This aspect of interpersonal relations is familiar to many signers, but is typically not known to hearing non-signers until they experience some embodied insight into what it might be like to be deaf and use a signed language (Kolb, 2016).

When Lina was too fast for the interpreters, Anna and Elvin missed out on crucial instructions, resulting in the emergence of their deafness as a barrier during these interactions. Luigi and Amanda tried to pass on information where they could, but the speed of the process made this difficult. Even if an instruction was intended only for themselves, they would feel guilty that this information was not accessible to everyone. Some of these issues were alleviated by pairing each deaf dancer with a hearing dancer as a duet, so that the direction and interpretation of creative development tasks were less likely to be misinterpreted. Luigi and Amanda also developed a practice of taking time to summarise after rehearsals, thus showing a more nuanced understanding of the effects of deaf and hearing bodies in space. However, these acts were essentially compromises to the temporal and spatial demands required for the complicated languaging undertaken 
in the studio, rather than the equitable adaptations originally envisioned by the deaf artists. As such, their combined effect is the continued presence of awkward - even painful - memories of existential not-understanding. These memories remain a sore point for the deaf artists.

Interestingly, when interpreters cancelled or rescheduled at short notice, the tension between compromise and adaptation abated. Occasionally Amanda or Jo would interpret for Anna and Elvin, but generally these circumstances forced the non-signing artists to communicate directly with the deaf artists. Suddenly, it was necessary for them to consider how to communicate visually and consecutively (typically via a mix of newly-acquired Auslan signs, English mouthing, pantomime and bodily demonstrations of dance movements) - an action that arguably depends upon noticing more, feeling more, because the comfort of using one's default language is removed. All the artists agreed this improved their overall group bond over time.

Indeed, the deaf dancers observed that while interpreters are vital to facilitating communication, their presence can sometimes create a barrier between signers and non-signers. The presence of interpreters can perpetuate resistance to changing one's communicative repertoire, perhaps by confirming existing beliefs about languages and how they work, while their absence can promote change, resulting in more effective adaptations. This observation suggests that in situations where interpreters are used, it may be useful to actively create opportunities for deaf/ hearing interaction both with and without the presence of interpreters. It also points to the value of direct communication for the labor of understanding - at the very least because it facilitates comprehension of the influence of deafness on the spatial and temporal unfolding of interactions, which are markedly different to the customs of those who hear (see also E. M. Green 2015, with respect to interactions between deaf signers). In turn, this increases one's commitment to understanding others' ways of being, and how they are realized in specific interactions.

\section{Managing the needs of other people}

The physical demands of time and space may be compounded by other factors, such as the varied needs of other people, which often compete with our own. In this case, other professional artists who were expected to contribute to the development of the work. During technical rehearsals, for example, the dancers were required to simply stand on the stage to enable testing of visual effects by Rhian, Richard and Russell. Sometimes this entailed darkness. This was problematic for the deaf artists, who consequently negotiated for there to be some 
lighting so they could see their interpreters. In turn, the interpreters used the torch function on their phone to shine light onto each other, or asked another dancer to direct light onto their signing. In cases where total darkness was required, interpreters were excluded from the space entirely. The work of communicating intent then fell to Amanda and Luigi, who could be on stage close to Anna and Elvin, and provide brief updates through physical movement. For this practice to be effective (and not disabling), an enhanced level of trust between individuals is required.

As Jo uses both signed and spoken communication practices, she was often perceived as mediator between the signers and non-signers, despite also needing mediating for herself. For example, she would gather ideas from the hearing artists and take them to the deaf artists, then return with their input. However, some artists observed that the flexibility to either speak or sign can create complications, especially when non-signers forget that being able to speak does not necessarily mean one can hear, or when the physical environment changes quickly. As a choreographer who sometimes observed rehearsals from the stalls, Jo also experienced an additional challenge when seated in the stalls facing the dancers (and therefore the other deaf people) on the stage. This meant she was sometimes facing in the same direction as interpreters, rather than opposite them and in view of their signing. At the same time, she could not visually monitor the faces of the hearing artists seated beside or behind her, because all would be attending to the stage in front of them.

Occasionally a hearing artist would move nearer to Jo to relay information, but mostly Jo depended on previous hours spent with Lina discussing the work, developing the choreography and putting the pieces together. This meant Jo often knew what Lina was working on with the dancers, and therefore did not always require interpretation. Indeed, it was sometimes more beneficial for Jo as a choreographer to instead sit where she could watch the dancers on stage and piece together their movements. Regardless, Jo commented these situations did force a choice about which was more important: watching the movements or seeing the words being spoken or interpreted into Auslan. It was not possible for her to achieve both at the same time in the way the hearing artists were able to do. One consequence was that the hearing artists could take up a stronger position in the theatre space. It is a further question (beyond the scope of this chapter) whether this translated to a stronger position for hearing members of the audience as well. Overall, this situation demonstrates the ways in which our own, important needs can compete with the multi-layered needs of other people interacting within the same space, and the isolation it is possible to experience, even when surrounded by other people like ourselves. 
Some artists interpreted pressures such as time constraints as resulting from the technical demands of the production more generally and the presence of strong creative visions - which would be occurring even if all the artists were hearing. In these cases, misunderstandings and moments of not-understanding were attributed to factors other than the use of signing or speaking, i.e. factors unrelated to deafness or deaf communication practices. These included differences in creative vision and personal preferences for how the production should unfold. This demonstrates how communicative intent from one source can be interpreted in different ways by different targets: deaf artists may experience the pressures of time and space as barriers to their communication needs, whereas hearing artists - whose communicative mobility is not as constrained by these pressures - may interpret the same as barriers to their professional desires. Regardless of how these acts are interpreted, both arrive at the same end: with the non-realization of their creative design in the performance, another manifestation of not-understanding.

The communication practices described above emerged in response to the constraints shaped by time, space and people that influence all face-to-face interactions, but which are exacerbated during interactions between signing and non-signing people. With respect to deaf language ecologies, if time is limited for some reason, deaf individuals may feel obliged to sacrifice some or all their access to communication. In this way, time constraints can especially contribute to the exclusion of deaf ecological norms from a space, such as the necessity of attending to one thing at a time. This can result in deaf individuals feeling like they are rushed through an interaction they do not understand. In turn, this can precipitate embodied memories of all the varied disabling interactions that constitute our shared history of deafness. The effects of emotion on the communication practices described here are explored in the next section.

\section{The emotional resonance of (not)understanding}

Not long after the explosive cracking at the start of the performance, the dancers reappear in filtered light with their faces bound in white tape (Figure 2). Dancing in unison with Luigi and Amanda, Anna moves to the front of the stage, her face and mouth still hidden. Taking short, gasping breaths held in suddenly until she is unable to breathe, Anna produces quick, bodily movements (derived from conventionalized Auslan signs) to tell us she is surrounded by people and cannot breathe. Ripping the tape from her face, she repeats her movements - enabling 
clearer identification of individual signs such as PEOPLE ${ }^{4}$, AROUND-ME $^{5}$, CANNOT $^{6}$, BREATHE $^{7}$, HOLD-IN ${ }^{8}-$ once her face is revealed (Figure 3). The tape sticks to her neck. Anna has something to say, but expresses it as if she has not been allowed to. "What the hell am I doing here?”, she signs. "I'm here alone. There are people here I've known a while, but do we go deep? No.” She is distressed.

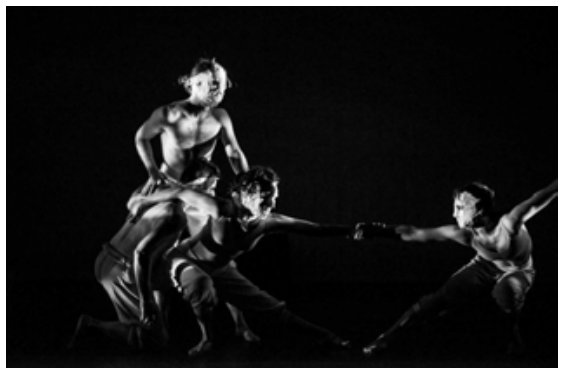

Figure 2. Dancers bound in white (image (C) Pippa Samaya).

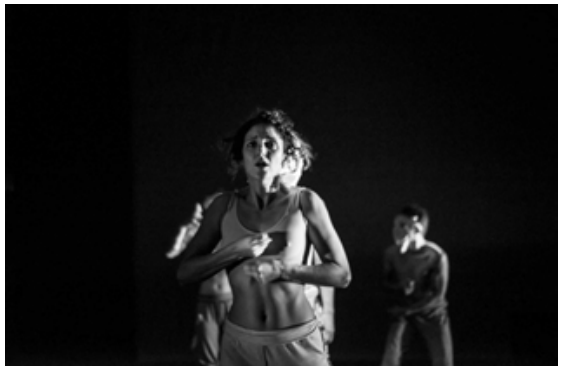

Figure 3. Anna talks to us (image (C) Pippa Samaya).

The role of affect and emotion in communication is often avoided in the scholarly literature, yet they are integral to the "powerful engines of social life" (Enfield \& Levinson, 2006), particularly regarding the symbolic expression of lived experience (Du Bois \& Kärkkäinen, 2012; see also Busch, 2015). As finely choreographed dance, the Auslan-based movements are too stylized and abstracted from everyday Auslan to be understood as regular conversation, yet several signing and non-signing viewers later observed (in the foyer of the theatre, after the show) that they somehow understood the intent of this expression, and indeed, identified with it. By creating the Auslan-based movement, then removing her mask to show her face, then repeating the movement, Anna effectively expresses an emotional intent that is not contingent on comprehending the signing as Auslan utterance - although the perception of Auslan signs does create a sense of self-identification for signers who are watching. Instead, it is the sequential unfolding and unified semiotic composition of these acts which enables a global understanding of her embodied expression, with the less language-like elements providing the

$4 \mathrm{http}: / /$ www.auslan.org.au/dictionary/words/people-1.html

$5 \mathrm{http} / / /$ www.auslan.org.au/dictionary/words/environment-2.html

$6 \mathrm{http}: / /$ www.auslan.org.au/dictionary/words/cannot-1.html

7 http://www.auslan.org.au/dictionary/words/breathe-1.html

$8 \mathrm{http}$ ://www.auslan.org.au/dictionary/words/hold-1.html 
emotional power. It is one thing to say you cannot breathe; it is another thing altogether to show someone what this looks like.

The organisation of the micro-moments within this dance sequence can be understood in the wider context of communicative moves, or turns, which are the "single, complete pushing forward of an interactional sequence by means of making some relevant social action recognizable” (Enfield, 2009: 11). We are watching Anna, therefore we are interacting with her, as she finds ways for us to recognise her communicative intent using the range of means at her disposal. This instance involves a combination of Auslan-derived dance with the white tape masking her face in a certain way, all produced in the specific setting of the darkened stage with other dancers in physical proximity. However, it could easily be some other semiotic composition, depending on one's creative vision, the semiotic resources available, and the spatiotemporal context in which the moves are done. In everyday Auslan use, for example, this composition typically involves integration of multilingual and highly conventionalized signs (including Auslan signs, English fingerspelling and mouthings) with tokens of symbolic indexicals and non-conventional signs, which are more heavily dependent on the context for interpretation (Clark, 1996; Enfield, 2009; see also Ferrara \& Hodge, 2018, and §2).

Essentially, the basis for the shared understanding that emerges between audience and dancers during Anna's performance is the same basis we use for communicating face-to-face using signed or spoken languages: the mutual orientation, recognition, and interpretation of social acts. It is the interaction of the elements within the composition that drives the creation of a "precise and vivid understanding" (Kendon, 2004: 174) not the use of language per se (see also Armstrong, Stokoe \& Wilcox, 1995). The preciseness and vividness of an understanding, however, might be clarified by using more overt and conventional semiotic strategies such as conventionalized words or signs. This is acknowledged by one of the dancers, Luigi. When asked how he best expresses himself, he replied:

Dancing is good for therapy, but writing is easier to share with someone because you can be more explicit - it can be difficult to be clear with dance, and to communicate in detail. Dancers need to be very good if they want to make the audience feel something.

This observation on the differences between dancing and writing (just two of many possible modes for expressing communicative intent) points to a tacit awareness that face-to-face communication - whether spoken, signed, or danced - emerges through disambiguating the physical and meaningful context of an interaction via the pluralistic expression of communicative intent (LaPolla, 2003). This requires interpreting both implicit and explicit information. In every- 
day communication, disambiguation is effected by combining ostensive acts (such as conventionalized signs and words, and the use of other bodily actions such as eye gaze and/or finger pointing to index people, things and ideas to the real or imagined space of the interaction) with the interpretations that others infer from these acts (LaPolla, 2003). Interactants can constrain each other's context to varying degrees of explicitness in different ways depending on the semiotic resources used.

For example, compare the following face-to-face spoken utterances made in response to an offer of a drink: (a) [points at soup], (b) "I have soup", (c) "No, because I have soup”, and (d) "No, I don't want anything to drink. Since I have soup, I don't need anything else to drink right now” (LaPolla, 2003: 116). Each response deploys bodily actions or spoken words in different ways, each effecting a different kind of inferential effort from the person offering a drink. In the context of a contemporary dance performance, interpreting a dance movement may involve arguably more inferential effort than everyday conversation. For example, a choreographer may intentionally leave a great deal of interpretation up to the audience, perhaps to some artistic ends. Conversely, a deaf signer likely may not want the possibility of understanding to be so open, or potentially vague, in their everyday communication ${ }^{9}$. Depending on how explicit one wants to be, it is typically a dancer or signer's skill level and the more conventional resources used (such as Auslan signs, or the physical movements derived from Auslan signs) that enable the degree of precision needed to clearly disambiguate some aesthetic quality or emotional resonance.

In both dance and everyday communication, however, this entails some recognition of what is/is not available in the communicative repertoire of other people, and how other's repertoires may/may not overlap with our own. The effort required for disambiguation is therefore magnified during interactions between signers and non-signers, for whom there are fewer conventionalized resources available. It is also present (more prosaically) during interactions between speakers or signers using a common language. Indeed, this unfolding closely resembles an earlier observation about Auslan (Johnston, 1996: 32):

There are grounds for believing, though detailed contextual analysis is needed to confirm this, that an Auslan text often unfolds in a spiral manner with a central event or proposition being stated and restated several times from different perspectives and in different ways with increasing embellishment and detail. In this way, the event or proposition is gradually 'brought into focus' and clarified.

9 I thank professional dancer and choreographer M. McGreevy for this comparison. 
This process of semiosis and gradual clarification - essentially the moment-bymoment laboring toward shared understanding - is also demonstrated by the interplay of the dancers with their shadows and images on the far wall of the stage. During the first half of the performance, Anna and Elvin rise and sign directly to each other, their shadows enlarging their actions on the white wall (Figure 4). However, while the movements produced by Anna and Elvin might be recognised by a signer as based on Auslan, it is only when one looks to their shadows on the wall that an understanding of the signing is possible. Here we can distinguish the handshapes and aesthetic quality of movement more clearly: what initially appears to be two people engaged in arm-heavy physical movement is framed in greater detail as a signed conversation in which neither is listening to the other. By itself, the Auslan-based movement is not enough to constrain our perception of what is happening on the stage. It is the use of light and shadow which illuminates the relevance of the communicative moves organized by the dancers, and therefore the emotional resonance of their refusing to do the work of understanding (see also Figure 5). These communicative acts are primordially driven by emotion, and this is evident in the result.

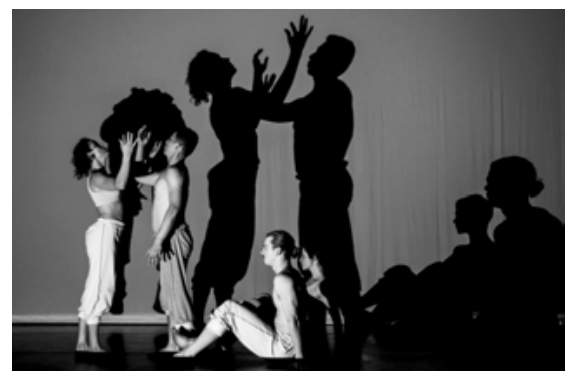

Figure 4. Anna and Elvin sign to each other (image (c) Pippa Samaya).

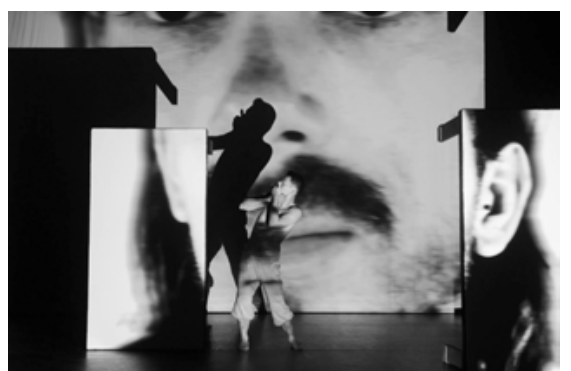

Figure 5. Elvin confronts himself (image (C) Pippa Samaya).

\section{Valuing the labor of (not)understanding}

The stage contracts with darkness again, and the dancers emerge cocooned in a breathing slip of rubber skin. They crawl out and transform the skin into a barrier separating them all: two dancers manipulate the tensile material while another struggles through the barrier (Figure 6). Leaning, stretching, rebounding from the rubber, they come together eventually, raw and exhausted. Slowly the dancers release the barrier and look for each other (Figure 7). They face towards each other, considering each other directly, regulating their breath. 
The light becomes gentle and soft, a reflection of the connection they are creating, as if each is saying, "Look at us - I am here; we are here together". It is not common to see people sustain eye contact for long periods of time. When this does happen, it is often the result of a struggle and a realization: something difficult had to happen before this moment in which we connect, making it more profound. This moment demonstrates how the acts of misunderstanding occurring in interactions between signers and non-signers (or between people with mismatched repertoires more generally) might be necessary for increasing the value of the understanding that does occur, and therefore the emotional resonance of the interaction.
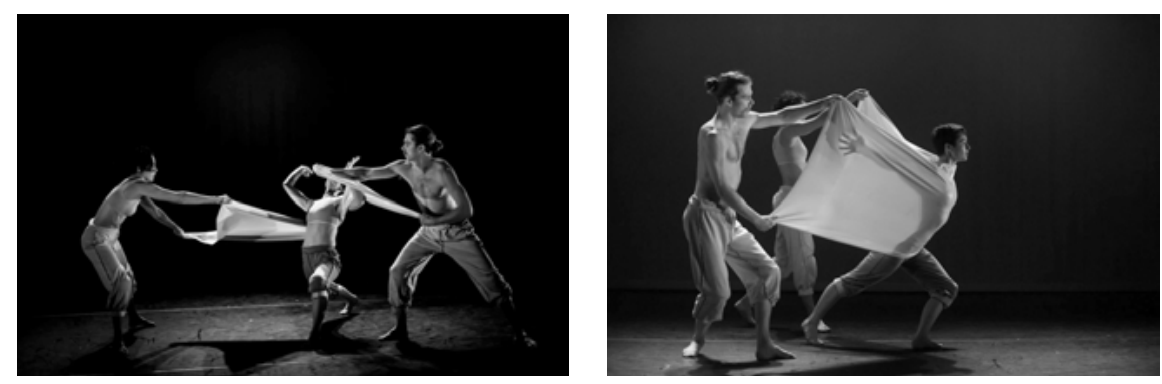

Figure 6. The barrier (image (c) Pippa Samaya).
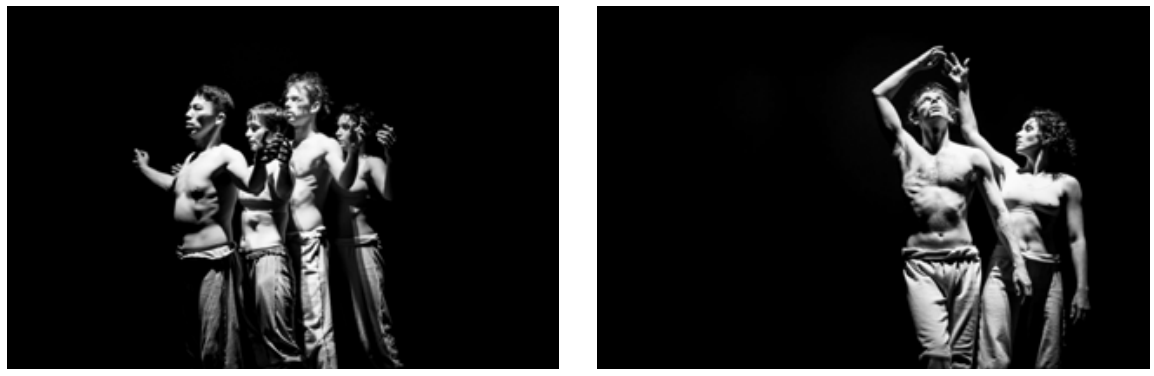

Figure 7. Looking for each other (image @ Pippa Samaya).

Reflecting on the performance, Luigi explicitly acknowledged the value of attending to faces, and the use of eye gaze to initiate and co-regulate social actions with his deaf colleagues. This is evidence of how a non-signer might effectively adapt their communicative repertoire for deaf languaging. The origin of this awareness lies in the need for dance cues to be visual: if they could not be visual, the responsibility of translating a specific auditory cue into a visual one fell to him. Luigi 
discovered he therefore used eye contact with the other dancers on stage to a far greater extent than would typically occur with non-deaf dancers. This behavior resulted in a much more connected unit, compared to other performances in which he had only relied upon auditory cues. In these cases, dancers do not look at each other directly, but rather out into the audience or down into themselves, resulting in a performance that is consequently less connected for both dancers and audience. The fact that Luigi acted on this awareness demonstrates his understanding of important differences between deaf and hearing bodies, and even how deaf ways of being might enrich his own experience and dance practice. He is determined to develop more eye contact with other dancers in the future.

The act of looking directly at someone is intense for both those doing the gazing, and the people who observe them. This intimacy carried through to the end of the performance, when the dancers reappear with their moving image projected onto the wall (Figure 8). Here their movements change. They slow down. No longer touching, but still synchronized, they are each a distinct entity. The theatre fades to black and the stalls shudder with the stamping feet of the audience. We take deep breaths and feel shocked. Moving images and silhouettes of the dancers appear standing at the back of the stage. The shape of their bodies visible, but lacking detail of who they are as people. Slowly they walk forward while being dimly lit from the side, making them more, but not fully, visible (Figure 9). They reach the front edge of the stage and are bathed in full light. Finally, they are fully realised, detailed people - indivisible and whole. They show us that when we are brave enough and tired enough to reveal and expose what is under our skin, both to ourselves and to others, we build a stronger shared understanding - one in which we may gradually be seen.

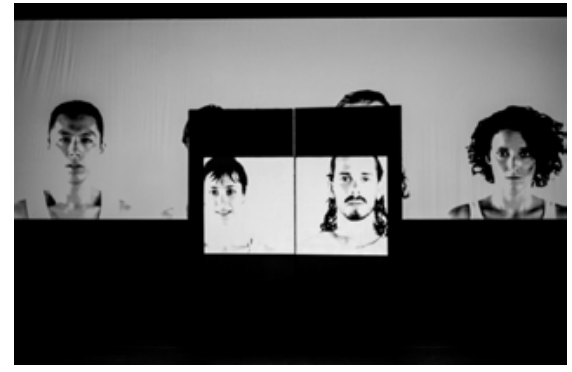

Figure 8. Moving images (image (C) Pippa Samaya).

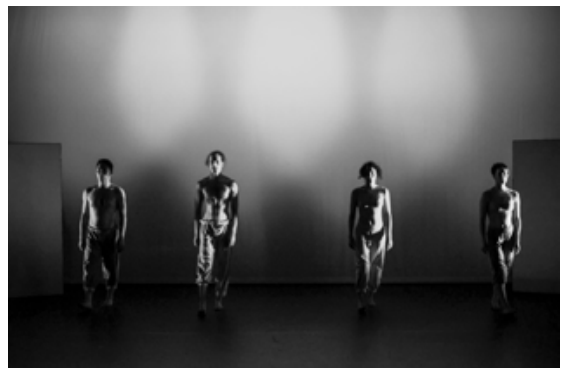

Figure 9. Walking forward (image (c) Pippa Samaya). 


\section{The geography of (not)understanding}

By coordinating the multi-sensory resources of movement, sound, video and light within the bounded space of the theatre, the artists in The Delta Project essentially mobilized a kind of idealized place in which deaf and hearing worlds are brought together. They achieved this by integrating Auslan-based choreographed movement, kinaesthetically-driven sound composition, digital video design, light and shadow into their performance. Analysis of one filmed performance and discussions with the artists reveals the communication practices that evolved during the development of the work are integral to this struggle. When deaf and hearing artists with varied language histories and pre-existing relationships collaborate on a creative work together, they naturally draw heavily upon their specific embodiments, personal beliefs, individual communication heuristics and shared communication practices. However, they also challenge each other to develop new ones, resulting in a complex language ecology in which subsequent interactions occur in new and adaptive ways. The result is a living geography of (not)understanding: one that is grounded in their experience of various intersubjective relations in which interactants notice/do not notice, comprehend/do not comprehend, and do/do not respond in turn.

The ideology of communication practices embedded in the final performance is one in which interactants actively realize that communication does not always work, even in the presence of professional interpreters hired to overtly mediate cross-modal interactions between different language users. Other, subtle affordances may instead assert more power in how these interactions unfold, such as different embodiments and the reality of different communicative repertoires colliding in a physical space. The nature of deafness means that some aspects of communication necessarily occur in different ways to spoken or written language interactions between people who can hear, particularly when it comes to managing the demands of time and physical space. It is also an ideology in which the individuals communicating do not always understand each other, but for reasons that are not simply attributable to the fact that others do or do not share the same communicative repertoire. These reasons may have more to do with conflicting personal beliefs, some of which may be linked to explicit ideas about language. It is entirely possible, for example, for individuals to simultaneously admire deaf signed language practices and resist the norms involved in using these practices effectively.

Yet the ideology embedded in Under My Skin is also one in which communicative intent can be realized pluralistically and with deep feeling. The data from the final performance and discussions with the artists described here demonstrate how it is not enough to simply learn the vocabulary and grammar of a 
signed language. Using a signed language, or learning to interact using a signed language because you are working with people who do, means adapting to the differences presented by deaf bodies - it means growing yourself into the collective 'skin' of deaf people who sign. Indeed, close interpersonal affinities between signers and non-signers can develop if each is attuned to the varied ways others labor towards understanding beyond their designated languages, such as by drawing on the full range of semiotic resources available during interactions. This involves developing one's sensitivity to the visual and kinaesthetic dynamics of an interaction (sign, dance, light, shadow), such as through attentive 'listening' (including meaningful use of eye gaze), and expanding one's communicative repertoire and awareness of different semiotic processes. These qualities may be revealed to non-signers in different ways, across different time depths. The nature of these revelations depends as much on an individual's personal beliefs and their commitment to understanding other people, as it does to the varied language histories of individuals, their personal agency and the dynamics of interacting personalities.

Regardless of how acts of communication manifest, both signers and non-signers organize their expression via sequentially unfolding communicative moves, in which various semiotic resources (including what we call 'language') combine. We also share the same drive to disambiguate the context of interpretation for others, such as by manipulating the preciseness and vividness of an understanding through the varied means available. However, this also entails becoming habituated to those ugly moments of not-understanding that contribute to what E. M. Green (2014: 142) aptly describes as "the sedimentation of failures and frustrations" familiar to deaf lives, such as when knowledge and understanding are sacrificed to the demands of time and space, or when others do not make allowances for the sequential contingency that deaf languaging requires. In addition to explicit ideas about language and analysis of the semiotic resources available during specific interactions, our understanding of language ideologies also depends on the more covert, subterranean affordances evidenced in this study, especially in the context of communication practices developed through interactions with members of minority language groups.

Despite the reality of how their varied communication practices evolved, all members of The Delta Project emerged from the collaboration with a better understanding of the role of communication in producing a creative work. As Amanda and Luigi had the most one-on-one contact with the two signing deaf dancers, their participation in this emerging language ecology is arguably the most sensitive of all the hearing artists. However, all the hearing artists felt their understanding of deaf ontologies and signed language has expanded through this collaboration. While it is unclear if the deaf artists experienced comparable benefits in gaining the main- 
stream experience they so badly wanted, they certainly progressed in their professional skill. Everyone wishes they could do the work again: another iteration, more of it, and in different places. There is power in it, so much more to explore.

During the group discussion, Richard commented that he was overwhelmed by the fact that several deaf people told him they felt like the performance was "made for them". In response, I asked if he had ever seen a performance that made him feel that way. He replied that he had seen a lot of art that resonated with him, but nothing he felt was specifically made for him. This was surprising to me. However, perhaps this feeling is an effect of living with the extremes of (not) understanding: a space, a performance, a moment being "made for you" when you do not usually feel that way can be transformative ${ }^{10}$. In this way (among the many other contributions to the realized and potential aesthetic value of the performance left unsaid here), Under My Skin is an artefact of the labor of understanding undertaken between the deaf and hearing artists involved in the collaboration. It is a testament to the willingness of deaf and hearing people to do this work.

\section{References}

Adam, Robert, Breda Carty \& Christopher Stone. 2011. Ghostwriting: Deaf translators within the Deaf community. Babel 57(4). 375-393. doi 10.1075/babel.57.4.01ada

Agha, Asif. 2005. Voice, footing, enregisterment. Journal of Linguistic Anthropology, 15(1). 38-59. https://doi.org/10.1525/jlin.2005.15.1.38

Agha, Asif. 2007. Language and social relations. (Studies in the Social and Cultural Foundations of Language no. 24). Cambridge, New York: Cambridge University Press.

Armstrong, David F., William C. Stokoe \& Sherman Wilcox. 1995. Gesture and the nature of language. Cambridge: Cambridge University Press.

Bagga-Gupta, Sangeeta. 2000. Visual language environments: Exploring everyday life and literacies in Swedish deaf bilingual schools. Visual Anthropology Review, 15: 95-120. doi 10.1525/var.2000.15.2.95

Bernstein, Basil. 2003[1971]. Class, Codes and Controle. London: Routledge.

Blackledge, Adrian, \& Angela Creese. 2010. Multilingualism: A Critical Perspective. London and New York: Continuum.

Bourdieu, Pierre. 1991. Language and symbolic power. Cambridge, Massachusetts: Harvard University Press.

Bühler, Karl. 1990[1934]. Theory of Language: The representational function of language. Philadelphia: John Benjamins Press.

Busch, Brigitta. 2012. The linguistic repertoire revisited. Applied Linguistics, 33(5). 503-23. doi.org/10.1093/applin/ams056

10 I thank E. M. Green for this point. 
Busch, Brigitta. 2015. Expanding the Notion of the Linguistic Repertoire: On the Concept of Spracherleben-The Lived Experience of Language. Applied Linguistics, 38(3). 340-358. doi.org/10.1093/applin/amv030

Byun, Kang-Suk, Connie de Vos, Anastasia Bradford, Ulrike Zeshan \& Stephen C. Levinson. 2017. First Encounters: Repair Sequences in Cross-Signing. Top Cogn Sci. doi:10.1111/ tops.12303

Clark, Herbert. H. 1996. Using Language. Cambridge: Cambridge University Press.

Du Bois, John W. \& Elise Kärkkäinen. 2012. Taking a stance on emotion: affect, sequence, and intersubjectivity in dialogic interaction. Text \& Talk, 32(4). 433-451. doi.org/10.1515/ text-2012-0021

Eades, Diana. 2008. Language and Disadvantage before the law. In T. M. Turell \& J. Gibbons (eds.). Dimensions of Forensic Linguistics. (pp. 179-195). Amsterdam: John Benjamins.

Enfield, Nicholas J. \& Stephen C. Levinson (eds.). 2006. Roots of human sociality: Culture, cognition and interaction. Oxford: Berg.

Enfield, Nicholas J. 2009. The Anatomy of Meaning: Speech, Gesture, and Composite Utterances. Cambridge: Cambridge University Press.

Fagan Robinson, Kelly. 2019. Conscious artistic translanguaging onstage. Applied Linguistics Review 2019; 10(1): 73-92. https://doi.org/10.1515/applirev-2017-0079

Ferrara, Lindsay \& Gabrielle Hodge. 2018. Language as description, indication, and depiction. Frontiers in Psychology, 9:716. doi 10.3389/fpsyg.2018.00716

Friedner, Michele. 2016. Understanding and not-understanding: What do epistemologies and ontologies do in deaf worlds? Sign Language Studies, 16(2). 184-203. https://www.jstor. org/stable/26191026

García, Ofelia. 2009. Education, multilingualism and translanguaging in the 21st Century. In Ajit K. Mohanty, Minati Panda, Robert Phillipson \& Tove Skutnabb-Kangas (eds.). Multilingual Education for Social Justice: Globalising the Local, 140-58. Orient BlackSwan.

Goodwin, Charles. 2000. Action and embodiment within situated human interaction. Journal of Pragmatics, 32.1489-1522. https://doi.org/10.1016/S0378-2166(99)00096-X

Green, E. Mara. 2015. One language, or maybe two: direct communication, understanding, and informal interpreting in international deaf encounters. In Michele Friedner \& Annelies Kusters (eds). It's a Small World: International Deaf Spaces and Encounters, 70-82. Washington DC: Gallaudet University Press.

Green, E. Mara. 2014. The nature of signs: Nepal's deaf society, local sign, and the production of communicative sociality. Unpublished doctoral dissertation. University of California, Berkeley.

Green, Jennifer. 2014. Drawn from the Ground: Sound, Sign and Inscription in Central Australian Sand Stories. Cambridge: Cambridge University Press.

Haugen, Einar. 1972. The ecology of language. In Anwar S. Dil (ed.). The ecology of language: Essays by Einar Haugen, 325-39. Stanford: Stanford University Press.

Johnston, Trevor. 1996. Function and medium in the forms of linguistic expression found in a sign language. In William H. Edmondson \& Ronnie B. Wilbur (eds.). International Review of Sign Linguistics, 57-94. Mahwah, NJ: Lawrence Erlbaum.

Johnston, Trevor. 2004. Whither the deaf community? Population, genetics, and the future of Australian sign language. Am. Ann. Deaf, 148(5). 358-75. doi 10.1353/aad.2004.0004

Kendon, Adam. 2004. Gesture: Visible Action as Utterance. Cambridge: Cambridge University Press. 
Kisch, Shifra. 2008. Deaf discourse: The social construction of deafness in a Bedouin community in the Negev. Medical Anthropology 27(3). 283-313. https://doi.org/10.1080/01459740802222807

Kockelman, Paul. 1999. Poetic function and logical form: ideal languages and forms of life. Chicago Anthropology Exchange, 29. 34-50.

Kolb, Rachel. 2016. The deaf body in public space. The New York Times, 28 September. https://www.nytimes.com/2016/09/28/opinion/the-deaf-body-in-public-space.html

Kral, Inge \& Elizabeth M. Ellis. 2008. Children, language and literacy in the Ngaanyatjarra Lands. In Jane Simpson \& Gillian Wigglesworth (eds.). Children's language and multilingualism: Indigenous language use at home and school, 154-172. London and New York: Continuum.

Kusters, Annelies. 2017. Gesture-based deaf-hearing customer interactions: Mumbaikars' multimodal and metrolingual strategies. International Journal of Multilingualism, 14(3). 283-302. https://doi.org/10.1080/14790718.2017.1315811

Kusters, Annelies, Massimiliano Spotti, Ruth Swanwick \& Elina Tapio. 2017. Beyond languages, beyond modalities: transforming the study of semiotic repertoires. International Journal of Multilingualism, 14(3). 219-232. doi:10.1080/14790718.2017.1321651

LaPolla, Randy J. 2003. Why languages differ: variation in the conventionalization of constraints on inference. In David Bradley, Randy J. LaPolla, Boyd Michailovsky \& Graham Thurgood (eds.). Language variation: papers on variation and change in the Sinosphere and in the Indosphere in honour of James A. Matisoff, 113-144. Canberra: Pacific Linguistics.

Moriarty Harrelson, Erin. 2017. Deaf people with "no language": Mobility and flexible accumulation in languaging practices of deaf people in Cambodia. Applied Linguistics Review, 10(1). 55-72. doi:10.1515/applirev-2017-0081

Napier, Jemina \& Lorraine Leeson. 2016. Sign language in action. London: Palgrave Macmillan.

Next Wave. 2016. Under My Skin, The Delta Project. Retrieved 15 October 2016: http://2016. nextwave.org.au/\# event=214

Nyst, Victoria. 2012. Shared Sign Languages. In Roland Pfau, Markus Steinbach \& Bencie Woll. (eds.) Sign language, 552-574. Berlin: Mouton de Gruyter.

Parmentier, Richard J. 1994. Sign in Society: Studies in Semiotic Anthropology. Bloomington \& Indianapolis: Indiana University Press.

Pickering, John. 1997. Beyond Cognitivism: Mutualism and Postmodern Psychology. In Paavo Pylkkänen, Pauli Plykkö \& Airi Hautamäki (eds.). Brain, Mind and Physics. Amsterdam: IOS Press.

Quinto-Pozos, David \& Robert Adam. 2013. Sign language contact. In Robert Bayley, Richard Cameron, \& Ceil Lucas (eds.). The Oxford handbook of sociolinguistics, 379-400. Oxford: Oxford University Press.

Snoddon, Kristin. 2017. Uncovering translingual practices in teaching parents classical ASL varieties. International Journal of Multilingualism, 14(3): 303-316. https://doi.org/10.1080 /14790718.2017.1315812

Tapio, Elina. 2013. A nexus analysis of English in the everyday life of FinSL signers: A multimodal view on interaction. Published doctoral dissertation, University of Oulu, Finland. Jyväskylä: Jyväskylä University Printing House. 
